\title{
ON THE THERAPEUTIC PROPERTIES OF NATURALLY OCCURRING FLAVONOID- QUERCETIN: A MAGICAL THERAPEUTIC AGENT
}

\author{
Keshav K Saini, N Manav, A K Bhagi and Amit Kumar* \\ Department of Chemistry, Dyal Singh College University of Delhi, New Delhi-110003, India
}

\begin{abstract}
Flavonoids are naturally occurring polyphenolic compounds which exhibit antioxidant properties. Quercetin is an important member of flavonoids family. It is a common ingredient in numerous food supplements like vegetables specially onion, citrus apples and olive oil. Apart from vegetables and fruits other sources are plant derived beverages like green tea and red wine. Recent studies show that it exerts potential health benefits due to its ability to scavenge various highly reactive free radical species generated during various metabolic activities. Studies claimed that it protects against aging, osteoporosis, pulmonary 5 and cardiovascular disease promotes balanced blood pressure and also protects from certain types of cancers. Consequently it stimulated interest in its study to collect scientific evidences for its various health benefits and to examine possible mechanism of its antioxidant activity and toxicological aspects. The aim of this review is to review the studies so far in order to elucidate the possible beneficial health effects of quercetin and to understand the possible mechanism involved in its antioxidant activity.
\end{abstract}

\section{INTRODUCTION}

Flavonoids are a special class of phytonutrients (plant chemicals) found in almost all vegetables and fruits in more or less quantity. Along with carotenoids, flavonoids are responsible for the various colors in fruits and vegetables. Flavonoids are the largest group of phytonutrients; they are further divided in various subclasses (Chart 1). Flavonoids are water soluble polyphenolic compounds which containing 15 carbon atoms. Flavonoids basically belong to polyphenolic compound family. All type of flavonoids contain a skeleton (Fig.1) of diphenylpropane in which two benzene rings (ring $A$ and $B$ ) attached with three carbon chain that forms a closed pyran ring (heterocyclic ring containing oxygen, the $C$ ring) generally, $\mathrm{B}$ ring is attached on $\mathrm{C}-2$ position of $\mathrm{C}$ ring, but it can also attach on 3 or 4 position of the ring. The flavonoids, one of the large and more diversified groups of phytochemicals due to the specific structural features of the ring $B$ and the way of glycosylation and hydroxylation of the three rings Their biological activities (potent antioxidants) also depends upon both on the structural characteristics and the pattern of glycosylation. Some of the bestknown flavonoids are quercetin and kaempferol.

*Corresponding author:

Email: akumardsc@gmail.com

http://dx.doi.org/10.20530/IJTA $32 \quad 20-27$

ISSN 2320-138X @ 2016

\section{Important subclasses of flavonoids}

Flavonoids Examples:

1. Flavonols Quercetin, Querctagetin, Kaempferol

2. Flavanols Silibinin, Taxifolin, Epicatechin

3. Flavanones Dihydroquercetin, Eriodictyol,

4. Flavones Nobiletin, Quercetogetin, Apegenin

5. Isoflavones Daidzein, Genistein ,Glycitein,

6. An'thocyanidins Cyanidin, Malvidin, Delphinidin

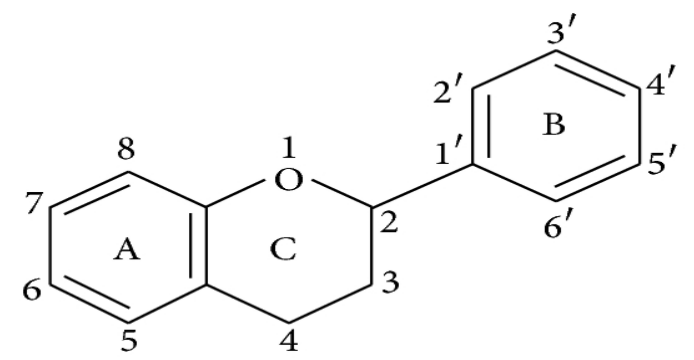

Fig. 1: Basic structure of flavonoids

\section{REACTIVE SPECIES -FREE RADICALS}

\section{Occurrence}

Chemically free radicals are neutral species with unpaired electron. The high reactivity of free radicals is due to presence of unpaired electron. They are produced in human body during various metabolic processes mainly in mitochondria and peroxisomes. Sometimes immune system's cells purposefully produce them to counter viruses and bacteria. Environmental factors such as pollution, radiations, $\mathrm{X}$-rays, cigarettes smoke, pesticides also responsible for production of free radicals. Oxidative 
phosphorylation involves reduction of oxygen to produce water. However small portion of the oxygen (1-3\%) remains partly reduced which can act as free radicals or oxidizes other compounds. These reactive species are known as reactive oxygen species (ROS). Similarly reactive nitrogen species (RNS) also formed. Some important ROS and RNS are hydroxyl radical $\left(\mathrm{OH}^{*}\right)$,singlet oxygen $\left({ }^{1} \mathrm{O}_{2}\right)$ superoxide ion $\left(\mathrm{O}_{2}^{-}\right)$, peroxyl radicals $\left(\mathrm{RO}_{2}^{-}\right)$, ozone $\left(\mathrm{O}_{3}\right)$, peroxides $\left(\mathrm{H}_{2} \mathrm{O}_{2}\right)$, nitric oxide (NO) and proxy nitrite (ONOO- $)^{-1}$ etc $^{1}$

\section{Chart 1}

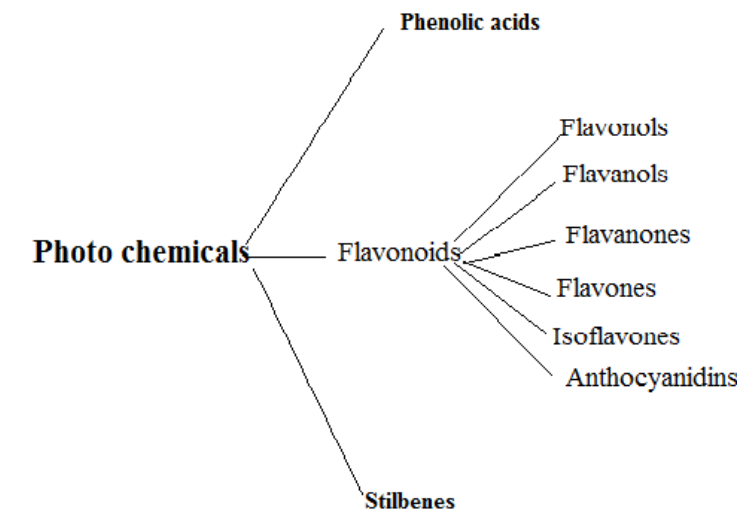

FUNCTION AND PURPOSE OF FREE RADICALS IN LIVING BEING

\section{A. Beneficial aspects}

ROS and RNS are beneficial at low concentration; these species are purposefully produced during various metabolic and other processes. They are part of body defense system. During attack of pathogenic microbes phagocytes (macrophages, neutrophils, monocytes) release free radicals to counter microbes as part of the body's defense mechanism ${ }^{2}$. During exercise when muscles become more active, they increase formation of ROS and RNS. These ROS and RNS are important signaling agents that help regulate acute responses to exercise as well as positive adaptations to training in the muscles. Therefore these active species are necessary for the smooth function of muscles ${ }^{3}$.

\section{B. Deleting effects}

The excess production of ROS and RNS causes imbalance between generation of these species and oxidative defense which result in oxidative stress. Oxidative stress is closely associated with damaging effects on various biomolecules including carbohydrate, proteins, DNA, RNA, and nucleic acids ${ }^{4}$. ROS and RNS can also damage mitochondrial
DNA which is supposed to be the main cause for several human diseases and also trigger the aging process $^{5}$. Free radicals mainly damage polyunsaturated fatty acids of the cell membrane. This oxidative deleting effect of polyunsaturated fatty acid is known as lipid peroxidation which proceeds by a chain reaction ${ }^{6}$. The process of lipid peroxidation involves attack of free radical $\left(R^{*}\right)$ on lipid molecule and oxidizes the lipid molecule by abstraction of hydrogen and form lipid free radical (Lip). This lipid free radical readily reacts with oxygen to form a lipid peroxyl radical (LipOO'). This lipid preoxyl radical is a carrier of the chain reaction which can enter in chain propagation step and oxidize new lipid molecule to produce lipid hydroperoxide (LipOOH).This lipid hydroperoxide may enter chain termination step and break down into either stable lipid alcohol or into aldehydes ${ }^{7}$. Studies show that 4-Hydroxy-2-nonenal is the most toxic while Malondialdehyde is most mutagenic product of lipid peroxidation ${ }^{8}$. Some of these aldehydes being biologically active in nature migrate from site of their production causing cell membrane damage and other disease.

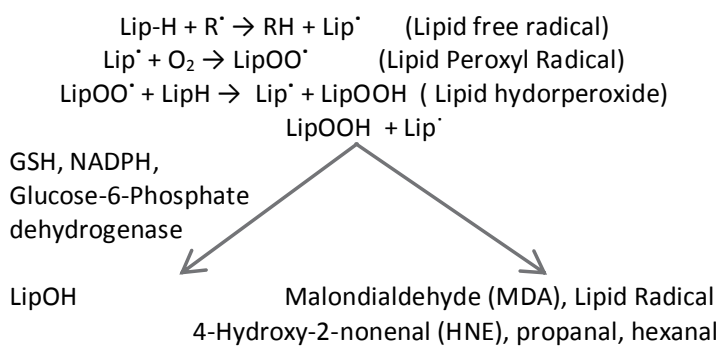

\section{Oxidative stress}

Oxidative stress is essentially the measure of an imbalance between the production of free radicals during various metabolic reactions and the ability of the body to counter or detoxify their harmful effects by antioxidant defense system. Cells produce free radicals during various metabolic processes and neutralize them through antioxidant defense system but sometimes over production of free radical causes an imbalance and cells failed to counter free radicals. The excess production of free radical cause short term or long term oxidative stress depending upon the concentration of free radicals. The excess free radicals damages biomolecules like lipids, carbohydrate, protein, DNA and RNA. Various diseases are associated with oxidative stress are given in Table 2. 


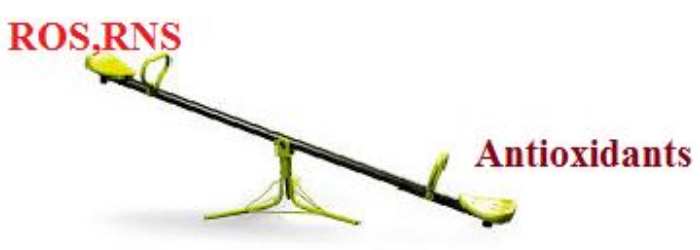

Oxidative stress

\section{Antioxidants}

The term "Antioxidant" refers to any substances is misleading. It is nothing but only a chemical property. It is basically a behavior of any compound to donate electrons and neutralize free radicals. Some substances which act as antioxidants in one chemical environment may act as prooxidants (electron acceptor) in a different chemical environment. Each antioxidant has unique chemical and biological behavior. A particular antioxidant counteracts certain type of free radicals. Antioxidants form the first line of the body defense system. Body's immune system uses them to check the free radicals and prevent them to exert damaging effects on vital cellular or biomolecular targets. Antioxidants transfer electrons to the free radicals, thereby forming more stable product from highly unstable free radicals. There are probably thousand substances which exhibit antioxidant properties. Antioxidants may be divided into enzymatic and non-enzymatic subclasses. Enzymatic antioxidants are basically enzymes and coenzymes that may show antioxidant properties. These are easily recycled and hence only small quantity is sufficient. Some examples are Superoxide Dismutase DHEA, Glutathione Peroxidase, Catalase, Coenzyme Q10 (Coenzyme), Melatonin.

Non -enzymatic antioxidants includes compounds of various classes that are generally Phytonutrients or Phytochemicals which exhibit<smiles>O=c1c(O)c(-c2ccc(O)c(O)c2)oc2cc(O)cc(O)c12</smiles>

Chart 2: Quercetin [2-(3, 4-dihydroxyphenyl)-3, 5, 7trihydroxychromen-4-one] antioxidant properties. They includes vitamins, flavonoids, glutathione (GSH), carotenoids (lutein, lycopene etc.) some minerals (Copper, Manganese, lodide, Zinc) etc

Table 1: Various diseases associated with oxidative stress

\begin{tabular}{|c|c|c|}
\hline \multirow{8}{*}{$\begin{array}{l}\text { Oxidative } \\
\text { Stress }\end{array}$} & EYE & $\begin{array}{l}\text { Degenerative retinal } \\
\text { damage cataractogenesis }\end{array}$ \\
\hline & Brain & $\begin{array}{lr}\text { Trauma } & \text { stroke, } \\
\text { Neurotoxins, Parkinson's } \\
\text { disease, } & \text { Alzheimer's } \\
\text { disease } & \end{array}$ \\
\hline & Skin & Burn Dermatitis, Psoriasis \\
\hline & Heart & $\begin{array}{lr}\text { Angioplasty } & \text { Keshan } \\
\text { disease } & \text { (Seleniun } \\
\text { Deficiency) } & \end{array}$ \\
\hline & Lung & Asthma, ARDS, Hyperoxia \\
\hline & Kidney & $\begin{array}{l}\text { Renal graft, } \\
\text { Glomeruloneph }\end{array}$ \\
\hline & Joint & Rheumatoid, Arthritis \\
\hline & $\begin{array}{l}\text { Multi } \\
\text { Organ }\end{array}$ & $\begin{array}{l}\text { Radiation, Aging, } \\
\text { Inflammatory-immune, } \\
\text { Diabetes, Injury Ischemia- } \\
\text { Reflow }\end{array}$ \\
\hline
\end{tabular}

\section{QUERCETIN}

\section{Chemistry of quercetin}

Quercetin is a member flavonoid family and it is categorized under one of the six subclasses of flavonoid as flavonol (Table-1). Chemical formula of quercetin is $\mathrm{C}_{15} \mathrm{H}_{10} \mathrm{O}_{7}$. It is a yellow crystalline powder. Chemically quercetin is a polyphenolic compound and its antioxidant activities are basically due to polyphenolic groups. The presence of free 3$\mathrm{OH}$ substituent increases stability of the quercetin radical. Quercetin is mainly present in quercetin glycoside form in which it is attached with one or two glucose molecules. Quercetin aglycol form is found in lesser quantity. Quercetin glycol form is more readily absorbed as compared to aglycol form ${ }^{9}$. Quercetin glycosides are metabolized in various organs and releases aglycol form. Numerous studies have been done on bioavailability of quercetin glycosides and its aglycol form.

\section{Beneficial Effects of quercetin}

\section{a) Quercetin as an antioxidant}

A number studies have claimed antioxidant properties of quercetin. Quercetin act as an 
excellent ROS/RNS scavenger due to presence of large number of phenoxy hydroxyl groups and conjugated $\pi$ orbitals which makes quercetin good donor of electrons or hydrogen, therefore it can scavenge free radicals easily ${ }^{10}$. It also reduces inflammation cause by free radicals. Scavenging activity of quercetin is due to presence of phenolic hydroxyl group on B ring and C3- position in the C ring. Free radicals which are produced in various metabolic processes may activate transcription factors which causes generation of proinflammatory cytokines. High level of cytokines often found in the patients which suffer from chronic inflammatory diseases ${ }^{10}$. Quercetin also protects from environmental factors which trigger free radicals production. Studies show that membrane of red blood cells is damaged by the free radicals which are produced due to smoking (cigarette tar $)^{12}$. The deleting effect on red blood cells due to smoking is prevented by the quercetin aglycone and its conjugate metabolites (Quercetin $\mathrm{O}-\beta$-glucuronide and Quercetin -3-O- $\beta$ glucoside). ${ }^{12}$

\section{b) Cancer}

Various studies so far indicated that quercetin has noticeable effective value in cancer therapy ${ }^{13}$. Studies also suggest that quercetin has potential chemo-preventive activity and it also show a unique anti-proliferative and apoptotic effect on cancerous cells, which make it effective against any neutral cancer treatment approach. Although mechanism is yet to understand but quercetin seems to arrest cell cycle either at the $\mathrm{G}_{1} / \mathrm{S}$ or $\mathrm{G}_{2} / \mathrm{M}$ transition state depending upon the cell type ${ }^{14}$. Studies suggest that quercetin's cancer-protecting effects result possibly from the modulation of estrogen-receptor pathways. Quercetin is helpful in arresting the processes involved in growth of the tumors, cell mutation, and side effects of conventional cancer treatments, such as radiation or chemotherapy. Quercetin treatment quenches the growth of various types of human cancers, including prostate, lung cancers, breast, leukemia, esophagus, colon, endometrial, and nasopharyngeal $^{15}$

\section{c) Cardiovascular Health}

Now a day's heart diseases are the major killers, which are responsible for about almost half of all the deaths. The low density lipoproteins (LDL) which is found in blood contain mainly poly unsaturated fatty acids. The oxidation of these lipid components in LDL is responsible for atherosclerosis ${ }^{9}$. The vessel wall made of smooth muscle cells, endothelial and macrophage which can produce free radicals. These free radicals cause lipid peroxidation ${ }^{16}$ due to high level of these oxidized lipids for a long period. Vessel walls are affected and start to generate foam cells and plaque the vessels and ultimately cause atherosclerosis. In addition to the formation of atherosclerosis plaques, oxidized LDL is also cytotoxic and can damage endothelial cells and play vital role in cardiovascular disease. Quercetin is very effective in cardiovascular disease. Studies have shown that intake of quercetin lower the heart disease and stroke incidence. Quercetin may help to reduce the risk of atherosclerosis, buildup of plaque in arteries which cause to heart attack or stroke. Quercetin prevents the oxidation of LDL which causes the heart disease. In a recent study, the effect of quercetin supplementation was evaluated on blood pressure in hypertensive humans. The results of the study shows that although the blood pressure was not altered in hypertensive patients as a result of quercetin supplementation, however, it had been found to have a marked effect in reducing the blood pressure in stage 1 hypertensive patients $^{17}$.

\section{d) Diabetes}

In vitro studies of quercetin in medium containing high concentration of sugar has proved to be inhibitor of lens aldose reductase, an enzyme that catalyzes the conversion of glucose to sorbitol and has important role in diabetic cataract ${ }^{18}$. Studies have also indicated quercetin to be useful in diabetic neuropathy and pain in straptozotic in induced diabetic rats $^{19}$. Quercetin supplementation has also been found to lower the plasma glucose, preserves pancreatic $\beta$-cell integrity function in rat models of diabetes ${ }^{20}$. Studies have also raised concerns about long term use of quercetin in diabetes as incidence of increase of cataract and renal cell carcinoma was earlier reported. It may be because of Quercetin acting as pro-oxidant with progression of diabetes ${ }^{21}$. A reduction in jolting pain, numbness and irritation was also observed on topical application of quercetin with vitamin $D_{3}$ and ascorbyl palmitate for 3-4 weeks to foot showing diabetic neuropathy ${ }^{22}$.

\section{e) Pain and Inflammation}

In vivo animal studies have shown that Quercetin has anti-inflamatory action. It helps to overcome the inflammatory response induced by high fat $\operatorname{diet}^{23}$. It has also reduced clinical signs of arthritis in rats ${ }^{24}$. A recent study has shown that Quercetin 
administration in rat after traumatic spinal cord injury leading to recovery of motor functions was observed in half of the animals ${ }^{25}$, although this recovery seems to be frequency and dose dependent $^{24}$.

Quercetin affects the L-Arginine-nitric oxide, serotonin, GABAergic and opioid system and relieves pain by inhibiting pronociceptive cytokine production and scavenges free radicals produced in inflammatory pain ${ }^{26}$. In vitro studies also support the anti inflammatory effect by inhibiting formation of cycloxygenase and lipoxygenase, the inflammation producing enzymes ${ }^{27}$. Human studies show a mixed response of quercetin as an anti inflammatory agent $^{28,29}$. In general it failed to prevent exercise induced increase in C-reactive proteins in athletes ${ }^{30}$ and also has no effect on TNF- $\alpha$ in healthy subjects even though plasma quercetine in levels were significant. In some studies it showed no effect on CRP but TNF- $\alpha$ was decreased ${ }^{29}$ when $150 \mathrm{mg} /$ day of quercetin was taken for six weeks.

\section{f) Allergy and Asthma}

In vivo studies of quercetin suggest that it has anti allergic ${ }^{31}$ and anti asthmatic activity ${ }^{32}$. It also has anti inflammatory effects on allergic airway inflammation and asthma. It reduces eosinophil and neutrophil counts and infiltration in lungs tissue ${ }^{33}$. In vivo studies suggest quercetin inhibits anaphylactic contraction of ileum muscles in guinea pig $^{34}$ and suppresses immunoglobulin $\mathrm{E}$ responses and plasma histamine against peanut proteins in rats ${ }^{35}$. Quercetin glycoside provides a significant relief of ocular symptoms but no relief of nasal symptoms by pollens $^{36,37}$.

\section{g) Alzheimer's disease (AD)}

Alzheimer's disease ( $A D)$ is the most common senile dementia in the world. A recent study evaluated the neuroprotective effect of quercetin (25 mg/kg) administration on aged triple transgenic AD model mice. The study shows that quercetin decreases extracellular bamyloidosis, tauopathy, astrogliosis and microgliosis in the hippocampus and the amygdala. The findings suggest that quercetin reverses histological hallmarks of $A D$ and protects cognitive and emotional function in aged mice. A recent study investigated the effect of 5hydroxytryptamine type 3 (5-HT3A) receptor channel activity on pain transmission, analgesia, vomiting, and mood disorders in mouse model. The results suggest that quercetin is useful as a natural agent to prevent the nausea or vomiting induced by anticancer agents by activation of 5-HT3A receptors in the central nervous system and those 5-HT3 receptor antagonists such as ondansetron.

\section{h) Quercetin and Skin health}

Quercetin has ability of blocking "mast cells," which are immune cells and responsible for triggering stress-induced anxiety, allergic reactions, inflammatory disease and autoimmune disease ${ }^{38}$. Normally mast cells migrate towards skin to deals with a wound or infection or injury. Studies show that stress implied injury on skin and induce the immune cells to migrate towards skin ${ }^{39}$. These mast cells release the inflammatory chemicals which are responsible of causing various skin problems, allergies, asthma and digestive diseases. These mast cells send communication to nerves which in turn cause anxiety. It is clear that skin problems, allergy, asthma and stress are linked with mast cells. Therefore stress can cause allergic reactions, skin problems or even could land in chronic breathing or skin problems. Since quercetin has ability to check mast cell therefore prevents form allergic reactions and other skin related problems by stopping mast cell by releasing histamine which causes irritation. Quercetin also shows protective effects on nervous system and help by quenching the release of many pro-inflammatory cytokines, such as IL-8 and TNF, which are responsible for skin inflammation, thus quercetin found to be helpful in skin related problems like dermatitis, allergy and photo sensibility ${ }^{40}$.

\section{i) Miscellaneous}

In recent interesting study, the possible action of a dietary flavonoid, quercetin, and a sphingolipid, sphingomyelin, was examined as functional foods in healthy animals. The results indicated that both substances modify small intestinal activity in healthy mice and alter intestinal enzymatic activity and nutrient uptake. The effects observed in the small intestine did not result in impair of normal development of the animals, as indicated by varied biochemical parameters.

\section{REFERENCES}

1. Boots AW, Haenen GRMM, Bast A. Health effects of quercetin: From antioxidant to nutraceutical. European Journal of Pharmacology. 2008 May;585(23):325-

37.Availablefrom:http://dx.doi.org/10.1016/j.ejphar.2 008.03.008 
2. Yao $Y$, Han DD, Zhang $T$, Yang Z. Quercetin improves cognitive deficits in rats with chronic cerebral ischemia and inhibits voltage-dependent sodium channels in hippocampal CA1 pyramidal neurons. Phytotherapy Research. 2010 Jan;24(1):136-40. Available from: http://dx.doi.org/10.1002/ptr.2902

3. Dröge W. Free Radicals in the Physiological Control of Cell Function. Physiological Reviews. 2002 Jan 1;82(1):47-95. Available from: http://dx.doi.org/10.1152/physrev.00018.2001

4. Young IS. Antioxidants in health and disease. Journal of Clinical Pathology. 2001 Mar 1;54(3):176-86. Available from: http://dx.doi.org/10.1136/jcp.54.3.176

5. McCord JM. The evolution of free radicals and oxidative stress. The American Journal of Medicine. 2000 Jun;108(8):652-9. Available from: http://dx.doi.org/10.1016/s0002-9343(00)00412-5

6. Park $\mathrm{Y}, \mathrm{Nam} \mathrm{S}, \mathrm{Yi} \mathrm{H}-\mathrm{J}$, Hong H-J, Lee M. Dietary n-3 polyunsaturated fatty acids increase oxidative stress in rats with intracerebral hemorrhagic stroke. Nutrition. 2009 Nov;29(11):812-8. Available from: http://dx.doi.org/10.1016/j.nutres.2009.10.019

7. Esterbauer H, Cheeseman KH, Dianzani MU, Poli G, Slater TF. Separation and characterization of the aldehydic products of lipid peroxidation stimulated by ADP-Fe $2+$ in rat liver microsomes. Biochemical Journal. 1982 Oct 15;208(1):129-40. Available from: http://dx.doi.org/10.1042/bj2080129

8. Esterbauer $\mathrm{H}$, Schaur RJ, Zollner $\mathrm{H}$. Chemistry and biochemistry of 4-hydroxynonenal, malonaldehyde and related aldehydes. Free Radical Biology and Medicine. 1991 Jan;11(1):81-128. Available from: http://dx.doi.org/10.1016/0891-5849(91)90192-6

9. Lobo V, Patil A, Phatak A, Chandra N. Free radicals, antioxidants and functional foods: Impact on human health. Phcog Rev. 2010;4(8):118. Available from: http://dx.doi.org/10.4103/0973-7847.70902

10. Gibellini L, Pinti M, Nasi M, Montagna JP, De Biasi S, Roat $E$, et al. Quercetin and Cancer Chemoprevention. Evidence-Based Complementary and Alternative Medicine. 2011;2011:1-15. Available from: http://dx.doi.org/10.1093/ecam/neq053

11. Boots AW, Wilms LC, Swennen ELR, Kleinjans JCS, Bast A, Haenen GRMM. In vitro and ex vivo antiinflammatory activity of quercetin in healthy volunteers. Nutrition. 2008 Jul;24(7-8):703-10. Available from: http://dx.doi.org/10.1016/j.nut.2008.03.023

12. Begum AN, Terao J. Protective effect of quercetin against cigarette tar extract-induced impairment of erythrocyte deformability. The Journal of Nutritional Biochemistry. 2002 May;13(5):265-72. Available from: 2863(01)00219-4

13. Zheng F-J. Effects of quercetin on the proliferation of breast cancer cells and expression of survivin in vitro. Exp Ther Med. 2013 Sep 3; Available from: http://dx.doi.org/10.3892/etm.2013.1285

14. Ong C, Tran E, Nguyen T, Ong C, Lee S, Lee J, et al. Quercetin-induced growth inhibition and cell death in nasopharyngeal carcinoma cells are associated with increase in Bad and hypophosphorylated retinoblastoma expressions. Oncol Rep. 2004 Mar 1; Available from: http://dx.doi.org/10.3892/or.11.3.727

15. Kaneuchi M, Sasaki M, Tanaka Y, Sakuragi N, Fujimoto $S$, Dahiya R. Quercetin regulates growth of Ishikawa cells through the suppression of EGF and cyclin D1. International Journal of Oncology. 2003 Jan 1; Available from: http://dx.doi.org/10.3892/ijo.22.1.159

16. Neužil J, Thomas SR, Stocker R. Requirement for, Promotion, or Inhibition by $\alpha$-Tocopherol of RadicalInduced Initiation of Plasma Lipoprotein Lipid Peroxidation. Free Radical Biology and Medicine. 1997 Jan;22(1-2):57-71. Available from: http://dx.doi.org/10.1016/s0891-5849(96)00224-9

17. Egert S, Bosy-Westphal A, Seiberl J, Kürbitz C, Settler $U$, Plachta-Danielzik $S$, et al. Quercetin reduces systolic blood pressure and plasma oxidised lowdensity lipoprotein concentrations in overweight subjects with a high-cardiovascular disease risk phenotype: a double-blinded, placebo-controlled cross-over study. $\mathrm{Br} J$ Nutr. $2009 \mathrm{Apr}$ 30;102(07):1065. Available from: http://dx.doi.org/10.1017/s0007114509359127

18. Chaudhry PS, Cabrera J, Juliani HR, Varma SD. Inhibition of human lens aldose reductase by flavonoids, sulindac and indomethacin. Biochemical Pharmacology. 1983Jul;32(13):19958 .Availablefrom:http://dx.doi.org/10.1016/00062952(83)90417-3

19. Anjaneyulu M, Chopra K. Attenuation of thermal hyperalgesia and cold-allodynia by PKC inhibitor and its combination with antioxidant, quercetin in STZinduced diabetic rats. The Journal of Pain. 2005 Mar;6(3):S37. Available from: http://dx.doi.org/10.1016/j.jpain.2005.01.144

20. Khaki A, Fathiazad F, Nouri M, Khaki A, Maleki NA, Khamnei HJ, et al. Beneficial effects of quercetin on sperm parameters in streptozotocin-induced diabetic male rats. Phytotherapy Research. 2010 Aug 19;24(9):1285-91. Available from: http://dx.doi.org/10.1002/ptr.3100

21. Hsieh C-L, Peng C, Cheng Y-M, Lin L-Y, Ker Y-B, Chang $\mathrm{C}-\mathrm{H}$, et al. Quercetin and Ferulic Acid Aggravate Renal Carcinoma in Long-Term Diabetic Victims. Journal of 
Agricultural and Food Chemistry. 2010 Aug 25;58(16):9273-80. Available from: http://dx.doi.org/10.1021/jf101580j

22. Valensi P, Le Devehat C, Richard J-L, Farez C, Khodabandehlou T, Rosenbloom RA, et al. A multicenter, double-blind, safety study of QR-333 for the treatment of symptomatic diabetic peripheral neuropathy. Journal of Diabetes and its Complications . 2005 Sep;19(5):247-53. Available from: http://dx.doi.org/10.1016/j.jdiacomp.2005.05.011

23. Stewart LK, Soileau JL, Ribnicky D, Wang ZQ, Raskin I, Poulev A, et al. Quercetin transiently increases energy expenditure but persistently decreases circulating markers of inflammation in C57BL/6J mice fed a highfat diet. Metabolism. 2008 Jul; 57:S39-S46. Available from: http://dx.doi.org/10.1016/j.metabol.2008.03.003

24. Mamani-Matsuda $M$, Kauss T, Al-Kharrat A, Rambert J, Fawaz F, Thiolat D, et al. Therapeutic and preventive properties of quercetin in experimental arthritis correlate with decreased macrophage inflammatory mediators. Biochemical Pharmacology . 2006 Nov;72(10):130410. Available from :http://dx.doi.org/10.1016/j.bcp.2006.08.001

25. Schültke E, Kendall E, Kamencic $H$, Ghong Z, Griebel RW, Juurlink BHJ. Quercetin Promotes Functional Recovery Following Acute Spinal Cord Injury. Journal of Neurotrauma. 2003 Jun;20(6):58391 .Availablefrom:

http://dx.doi.org/10.1089/089771503767168500

26. Filho AW, Filho VC, Olinger L, de Souza MM. Quercetin: Further investigation of its antinociceptive properties and mechanisms of action. Archives of Pharmacal Research. 2008 Jun;31(6):713-21. Available from: http://dx.doi.org/10.1007/s12272001-1217-2

27. Lee $K M$, Hwang $M K$, Lee $D E$, Lee $K W$, Lee $H J$. Protective Effect of Quercetin against ArseniteInduced COX-2 Expression by Targeting PI3K in Rat Liver Epithelial Cells. Journal of Agricultural and Food Chemistry. 2010 May 12;58(9):5815-20. Available from: http://dx.doi.org/10.1021/jf903698s

28. Egert S, Wolffram S, Schulze $B$, Langguth $P$, Hubbermann EM, Schwarz K, et al. Enriched cereal bars are more effective in increasing plasma quercetin compared with quercetin from powderfilled hard capsules. $\mathrm{Br} J$ Nutr. 2011Jul20;107(04):53946.Availablefrom:http://dx.doi .org/10.1017/s0007114511003242

29. Egert S, Boesch-Saadatmandi C, Wolffram S, Rimbach G, Muller MJ. Serum Lipid and Blood Pressure Responses to Quercetin Vary in Overweight Patients by Apolipoprotein E Genotype. Journal of Nutrition.
2009 Dec 23;140(2):278-84. Available from: http://dx.doi.org/10.3945/jn.109.117655

30. McAnulty SR, McAnulty LS, Nieman DC, Quindry JC, Hosick PA, Hudson $\mathrm{MH}$, et al. Chronic quercetin ingestion and exercise-induced oxidative damage and inflammation. Applied Physiology, Nutrition, and Metabolism. 2008 Apr;33(2):254-62. Available from: http://dx.doi.org/10.1139/h07-177

31. Fox C, Wolf E, Kageysobotka A, Lichtenstein L. Comparison of human lung and intestinal mast cells. Journal of Allergy and Clinical . 1988 Jan;81(1):89-94. Available from: http://dx.doi.org/10.1016/00916749(88)90225-4

32. Moon H, Choi HH, Lee JY, Moon HJ, Sim SS, Kim CJ. Quercetin inhalation inhibits the asthmatic responses by exposure to aerosolized-ovalbumin in conscious guinea-pigs. Archives of Pharmacal Research . 2008 Jun;31(6):771-8. Available from: http://dx.doi.org/10.1007/s12272-001-1225-2

33. Rogerio AP, Kanashiro A, Fontanari $C$, da Silva EVG, Lucisano-Valim YM, Soares EG, et al. Antiinflammatory activity of quercetin and isoquercitrin in experimental murine allergic asthma. Inflammation Research . 2007 Oct;56(10):402-8. Available from: http://dx.doi.org/10.1007/s00011-007-7005-6

34. Fanning MJ, Macander P, Drzewiecki G, Middleton, Jr. E. Quercetin Inhibits Anaphylactic Contraction of Guinea Pig Ileum Smooth Muscle. International Archives of Allergy and Immunology . 1983;71(4):3713.Availablefrom:http://dx.doi.org/10.1 $159 / 000233423$

35. Behroo L, Shishehbor F, Ghafouriyan Broujerdnia M, Namjouyan F, Latifi S-M. Quercetin-gavaging quashes anaphylaxis sequela in the peanut sensitised wistars. Clin Transl Allergy. 2015;5(Suppl 3):P145. Available from: http://dx.doi.org/10.1186/2045-7022-5-s3p145

36. Hirano T, Kawai M, Arimitsu J, Ogawa M, Kuwahara Y, Hagihara K, et al. Preventative Effect of a Flavonoid, Enzymatically Modified Isoquercitrin on Ocular Symptoms of Japanese Cedar Pollinosis. Allergology International. 2009;58(3):373-82. Available from: http://dx.doi.org/10.2332/allergolint.08-oa-0070

37. Kawai M, Hirano $T$, Arimitsu J, Higa S, Kuwahara $Y$, Hagihara K, et al. Effect of Enzymatically Modified Isoquercitrin, a Flavonoid, on Symptoms of Japanese Cedar Pollinosis: A Randomized Double-Blind PlaceboControlled Trial. International Archives of Allergy and Immunology. 2009;149(4):359-68. Available from: http://dx.doi.org/10.1159/000205582

38. Li H, Zhao X, Ma Y, Zhai G, Li L, Lou H. Enhancement of gastrointestinal absorption of quercetin by solid lipid nanoparticles. Journal of Controlled Release. 
International Journal of Therapeutic Applications, Volume 32, 2016, 20-27

2009Feb;133(3):238-44.Availablefrom: http://dx.doi.org/10.1016/j.jconrel.2008.10.002

39. Mulholland PJ, Ferry DR, Anderson D, Hussain SA, Young AM, Cook JE, et al. Annals of Oncology. 2001;12(2):245-8. Available http://dx.doi.org/10.1023/a:1008372017097
40. Nishijima T, Iwai K, Saito $Y$, Takida $Y$, Matsue $H$. Chronic Ingestion of Apple Pectin Can Enhance the Absorption of Quercetin. Journal of Agricultural and Food Chemistry. 2009 Mar 25;57(6):2583-7. Available from: $\quad$ http://dx.doi.org/10.1021/jf803547h Barrenetxe J, Aranguren P, Grijalba A, MartínezPeñuela JM, Marzo F, Urdaneta E. Effect of dietary quercetin and sphingomye 